\title{
Emergency Light with Remote Control using Microcontroller
}

\author{
Anthoinete P.Y. Waroh \\ Computer Engeenering Dept \\ Manado State Polytechnic \\ North Sulawesi - Indonesia
}

\author{
Tony J. Wungkana \\ Electrical Engeenering Dept \\ Manado State Polytechnic \\ North Sulawesi - Indonesia
}

\author{
Sukandar Sawidin \\ Information Technology Dept \\ Manado State Polytechnic \\ North Sulawesi - Indonesia
}

\author{
Herry Makapedua \\ Electrical Engeenering Dept \\ Manado State Polytechnic \\ North Sulawesi - Indonesia
}

\begin{abstract}
The need for Remote Control systems is increasing, making it easier for humans to be able to optimize performance on the job over time. If at night there is a blackout, either due to weather, flood or disruption to the PLN electricity network or load regulation during peak load times so that electricity is turned on alternately for certain areas. As a result, the house was completely dark. Usually we turn on emergency lights for emergency lighting, or install a generator as a substitute for an electric generator from PLN.

This study aims to easily control emergency lights remotely so that users can turn on and turn off emergency lights by using a remote control, infrared (IR) sensor as receiver, LED as indicator and battery (12 Vdc battery) as a power source.

The Arduino Uno microcontroller is used as a tool for processing data from the system which functions to send commands to relay drivers to turn on and turn off emergency lights. The methodology used is the design method by making a prototype emergency lamp with remote control.

The test results show that the remote control can turn on and off 4 emergency lights according to the user's wishes. The 5 Ah battery can supply 4 emergency lamps for \pm 2 hours. The ability of the IR (Infrared) sensor to detect signals from a remote distance of approximately 6 meters.
\end{abstract}

\section{General Terms}

Remote Control, Infrared Sensor

\section{Keywords}

Driver Relay, Mikrokontroler Arduino Uno, Emergency Light

\section{INTRODUCTION}

Electric power is a basic requirement in everyday life, both for lighting the room at night and for electronic goods. With electricity, electronic equipment such as lights and others can be operated.

If at night there is a power cut from PLN causing the atmosphere of the house to become completely dark, we usually turn on some emergency lights for emergency lighting, or install a generator as a replacement for the electricity generator from PLN.

To operate the lighting in the house is still done manually by pressing the on/off button of the light switch, so this is less efficient in controlling the electric light. One solution to overcome this problem is by applying a tool that can control remotely easily, namely by using a remote control.

Remote Control is a portable device that can be used to turn on or connect and cut off electricity remotely without using a connecting cable. Remote control equipment uses a set of transmitters and receivers and drives a relay that functions as a breaker and connects electricity, while the transmitter and receiver function as transmitters and receivers of digital signal data to infrared.

Then an emergency light control system will be designed with Remote control in controlling the switch of electric power with a battery using an Arduino Uno microcontroller.

\section{LITERATURE REVIEW}

\subsection{Communication Using Infrared}

Infrared light is light that is not visible to the eye. Infrared light can travel through media such as air, water, optical fibers and translucent materials. The light source used as infrared is an infrared LED (Light Emitting Diode). LEDs are pn junction semiconductors that emit light when given a forward bias. As shown in Figure 1.

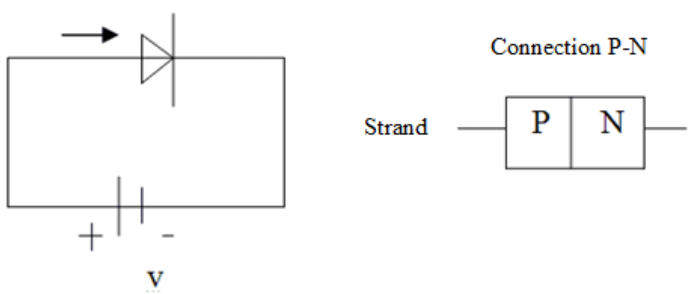

Figure 1. LED Strand

\subsubsection{How Infrared (IR) Works}

For data transmission using air as an intermediary medium, usually using a carrier frequency of around $30 \mathrm{KHz}$ to 40 $\mathrm{KHz}$. Infrared transmitted through the air is most effective when using a carrier signal that has a frequency above. The signal emitted from the sender is received by the infrared receiver and then decoded as a binary data packet. In serial data communication, the idle condition (no data transmission) is a logic ' 0 ', while in infrared communication the idle condition is a condition where there is no carrier signal. This is intended to prevent a waste of power when data transmission does not occur. 
Remote control uses infrared signal transmission which is modulated with a carrier signal with a certain frequency, namely at a frequency of $30 \mathrm{KHz}$ to $40 \mathrm{KHz}$. The signal emitted by the sender is received by the infrared receiver and then decoded as a binary data packet. In infrared transmission, there are two very important terminologies, namely: 'space' which states there is no carrier signal and 'pulse' which states there is a carrier signal as in Figure 2:

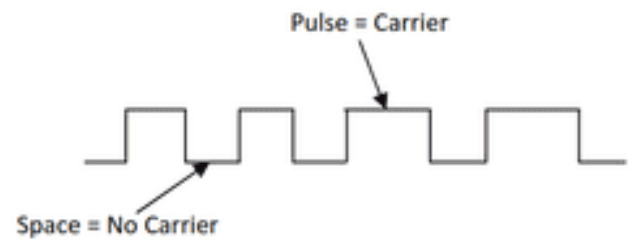

Figure 2. Carrier Signals in Infrared Transmission

For data transmission, the signal is transmitted in the form of pulses. When a button is pressed on the remote control, infrared will transmit a signal which will be detected as a binary data sequence.

Infrared rays emitted by infrared transmitters certainly have certain rules so that the transmitted data can be received properly at the receiver. Therefore, both the infrared sender and the receiver infrared must have the same rules in transmitting (the sending part) and receiving the signal then decoding it back into binary data (receiving part). Components that can receive infrared are light sensitive components that can be a diode (photodiode) or a transistor (phototransistor). This component will convert light energy, in this case infrared light energy into pulses of electrical signals.

This component must be able to collect as many infrared signals as possible so that the resulting pulses of electrical signal are of good quality.

\subsubsection{IR VS- $1838 B$}

IR sensor On the VS-1838B IR sensor, the logic used is high logic, after the logic is low for a moment and that is what is used as data, so by adjusting the pulse width high (1), it is with a certain value and makes that value as the data, then data transmission can be done. The physical form of this sensor can be seen in Figure 3.

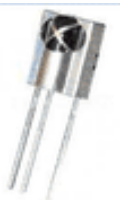

Figure 3. The VS-1838B IR sensor has electrical

characteristics, which is a logic high (1) or a voltage of \pm 4.5 volts at the output if this IC gets infrared rays with a frequency between $38-40 \mathrm{Khz}$, and this IC will issue The signal is Low (0) or the voltage is \pm 0.109 volts if the infrared ray emission with a frequency between $38-40 \mathrm{KHz}$ stops, but the logic low is only for a moment, which is around $1200 \mu \mathrm{s}$. After that, the output will return to high. This property is used as data transmission.

The output of this IC is connected to the microcontroller, so that every time this IC issues a low or high logic on its output, the micro can immediately detect it.

Infrared communication is done by using an infrared diode as a transmitter and an infrared receiver module as the receiver. For a distance of 3-5 meters, the data transmission must be modulated in advance to avoid damage to data due to noise. Infrared waveform can be seen in Figure 4.

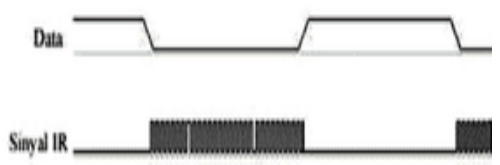

Figure 4. Infrared Wave Form

The modulation process is carried out by changing the logic conditions 0 and 1 to exist and there is no infrared carrier signal ranging from $30 \mathrm{KHz}$ to $40 \mathrm{KHz}$. The form of infrared modulation can be seen in Figure 5.

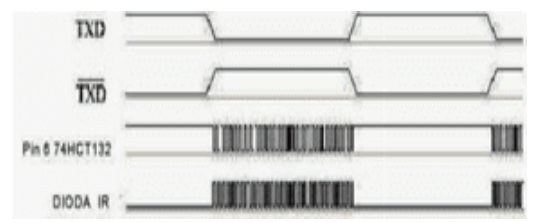

Figure 5. Forms of Infrared Modulation

\subsection{Microcontroller Arduino Uno}

Microcontroller Arduino Uno is an electronic circuit that is open source and has hardware and software that are easy to use. The Arduino can recognize the surrounding environment through various types of sensors and can control lights, motors and various types of actuators. Arduino has many types, including Arduino Mikro, Arduino Uno, Arduino Mega 2560, Arduino Fio, and others. (www.arduino.cc)

\subsection{Power Supply}

A power supply has 4 main parts in order to produce a stable DC current. The four main parts include the Transformer, Rectifier, Filter and Voltage Regulator. As in Figure 6.

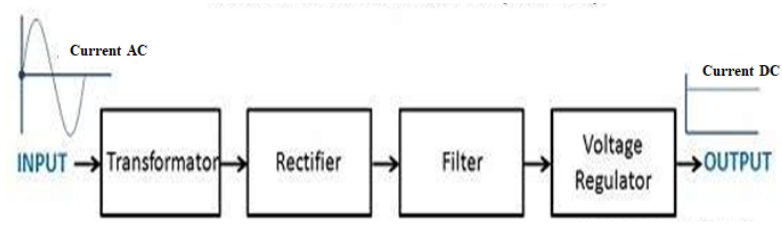

Figure 6. Block Diagram of Power Supply DC

Power Supply is a rectifier filter system that converts alternating voltage (AC) to direct voltage (DC). The conversion process starts with the transformer, rectifier, smoothing the ripple voltage (Ripple Voltage Filter) using a capacitor and regulation by a regulator circuit. So that the DC current is obtained.

\subsection{Batteries (Accumulator)}

Batteries are a source of direct current used in electric centers. the battery should always be charged via the rectifier as shown in Figure 7.

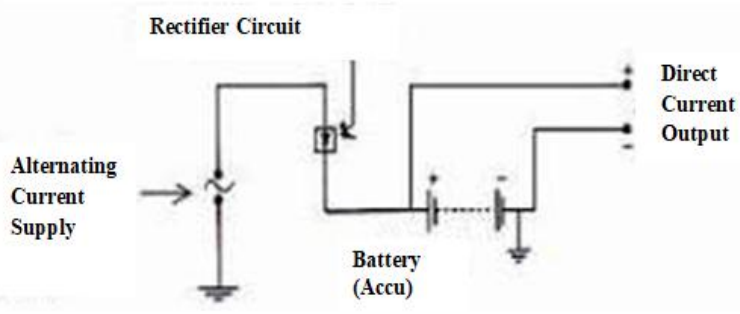

Figure 7: Battery Installation and Chargers 
Install the battery and its charging. The negative pole of the battery should be earthed to facilitate detection of ground connection faults in direct current installations. There are 2 kinds of batteries that can be used in the power center. Namely acid batteries with lead and wet batteries using nickel cadmium as poles.

1. Lead acid batteries use $\mathrm{PbO} 2$ as the positive pole and the negative pole is $\mathrm{Pb}$. Meanwhile, as an electrolyte used $\mathrm{H} 2 \mathrm{SO} 4$ sulfuric acid solution.

2. The nickel cadmium wet battery uses nickel oxyhydroxide $(\mathrm{NiOH})$ as the positive pole and cadmium $(\mathrm{Cd})$ as the negative pole. Meanwhile, as an electrolyte, a solution of caustic potassium $(\mathrm{KOH})$ is used.

For hot areas with temperatures above $250 \mathrm{C}$, lead acid batteries are more suitable than nickel cadmium alkaline batteries.

\section{METHODOLOGY}

This research uses a design method which begins with making a system block diagram, system flow chart, designing a power supply for the Automatic Charger, Arduino Uno Microcontroller and LCD. Designing the IR sensor to detect signals from the remote control, making the Arduino program a system control center that functions to receive data from sensors and process the data then activate the lamp loads with the relay driver and manufacture an emergency lamp control prototype with remote control then perform system testing and evaluation of hardware and software.

\section{RESULT AND DISCUSSION}

\subsection{Emergency Light Control System} Block Diagram

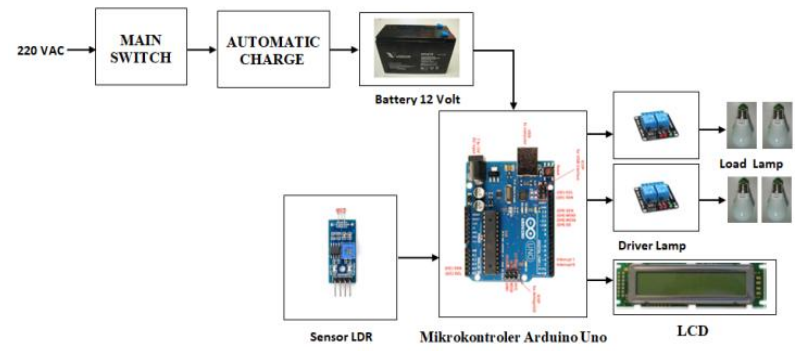

Figure 8. System Block Diagram System Block

Description Diagram in Figure 8:

Electricity source PLN will charge the battery automatically
(Automatic Charge) until the maximum voltage (12 Volt DC), after the maximum PLN power source is automatically disconnected (there is a LED light on as an indicator).

When the PLN is off, the system will work to turn on the emergency lights which can be adjusted with the Remote Control. The Arduino Uno Control System will get a power supply from the battery, so it will work when the PLN power source goes out.

By selecting a signal from the Remote Control, the Infrared sensor will activate to provide input to the Arduino Uno control system, after processing the result will activate the relay driver to turn on / off the lamp and can be monitored on the LCD which Emergency lights are turned on/off.

\subsection{Automatic Charger Design Schematic}

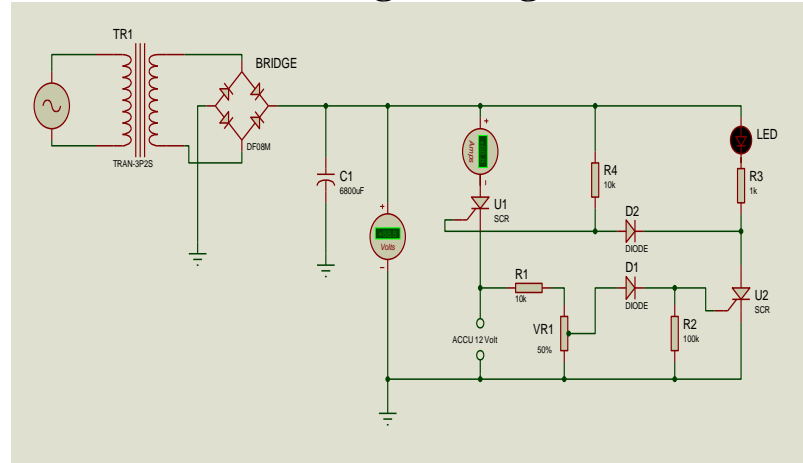

Figure 9. Battery Charging Circuit

When the battery is empty, the battery is connected to the charging terminal (figure 9) SCR U1 will be active because current flows through R4 and triggers the gate leg of SCR U1 to charge the battery (12-Volt Accu). If the battery is fully charged, the led indicator will light up and break the battery charge cycle.

\subsection{Emergency Light Control System Design}

In Figure 10. shows a series of emergency light control system designs.

When the PLN electricity goes off, the Relay will work so that the control equipment gets a supply from the battery ( 12 Volt $5 \mathrm{Ah} \mathrm{Accu}$ ). If button 1 on the remote is pressed (IR1) then the L1 lamp will light up, if the 1 button on the remote is pressed again then the L1 lamp will go out. Likewise, for remote buttons 2,3 and 4 . 


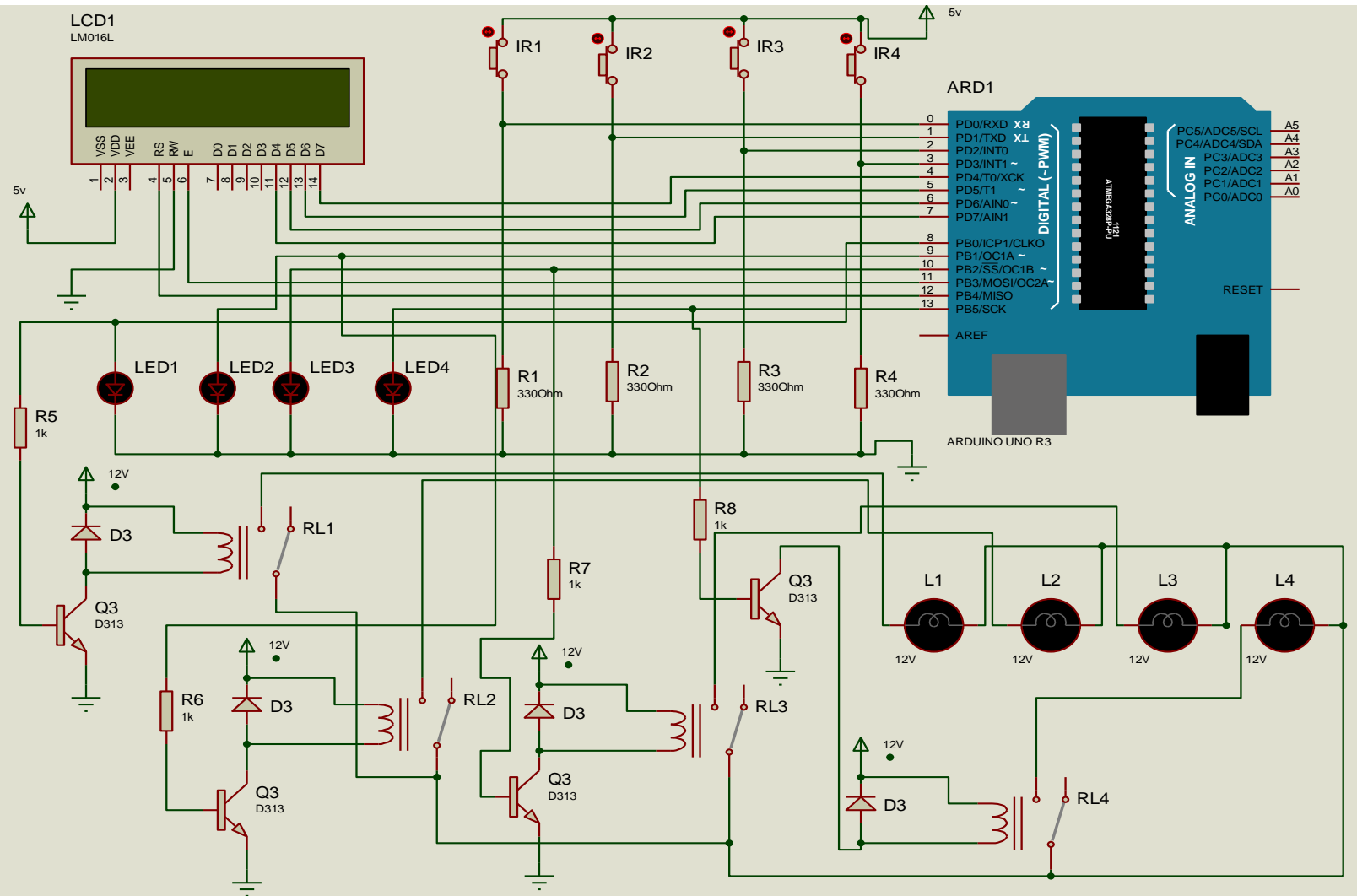

Figure 10. Emergency Light Control System Design Circuit

\subsection{Emergency Light Control System} Flowchart

\subsubsection{Battery Charging Flowchart}

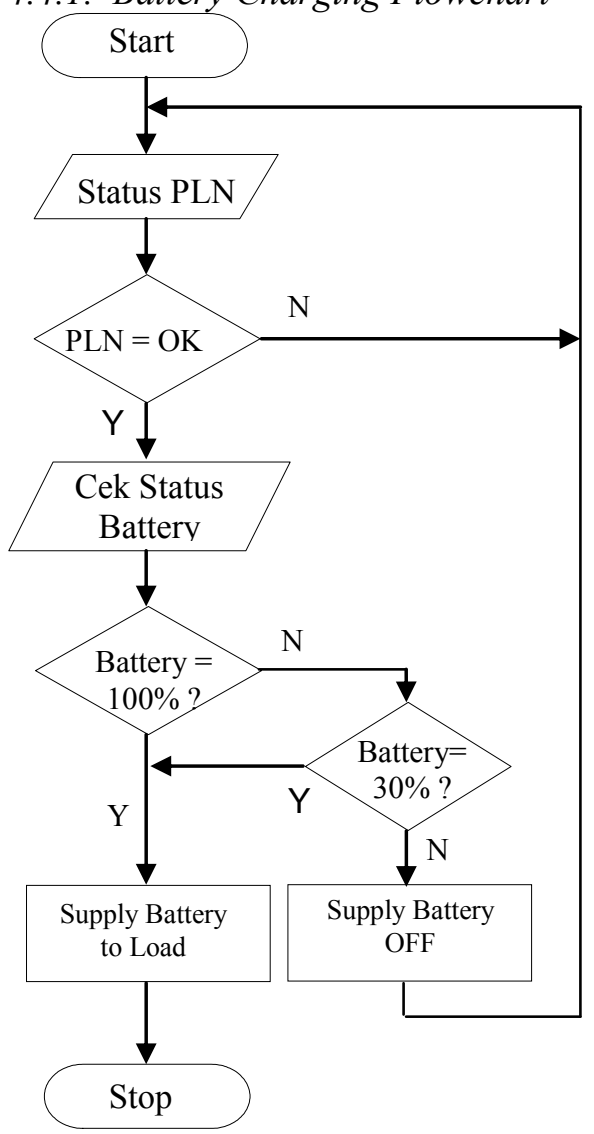

Figure 11. Battery Charging Flowchart
Explanation of Figure 11:

1. Start.

2. Power source from PLN is active.

3. Check the status of the battery

4. When the battery is full, the lamp load can be activated

5. If the battery is not full $<=30 \%$ then the lamp load cannot be activated.

6. Completed

\subsubsection{Emergency Light Control Flowchart}

In Figure 12 shows the Emergency Light Control Flow Chart. Explanation of the flow chart:

1. Start,

2. Initialize hardware; microcontroller used, call the library (prepare commands when using the microcontroller).

3. If the PLN power source goes out, the relay will automatically move the power supply to the battery to supply the control system circuit.

4. When the button 1 on the remote is pressed then the relay1 driver is active and lamp1 will turn on, when button 1 is pressed again lamp1 turns off.

5. When the button 2 on the remote is pressed then the relay 2 driver is active and the lights will light up, when the button 2 is pressed again the lights turn off.

6. When button 3 on the remote is pressed then the relay 3 driver is active and lamp 3 will turn on, when 
button 3 is pressed again lamp3 turns off.

7. When the button 4 on the remote is pressed then the relay 4 driver is active and lamp 4 will turn on, when button 4 is pressed again the lamp 4 turns off.

8. When you press the button 5 on the remote then the lights $1,2,3,4$ will light up, when the button 5 is pressed again the lights 1,2,3,4 will turn off.

9. Done.

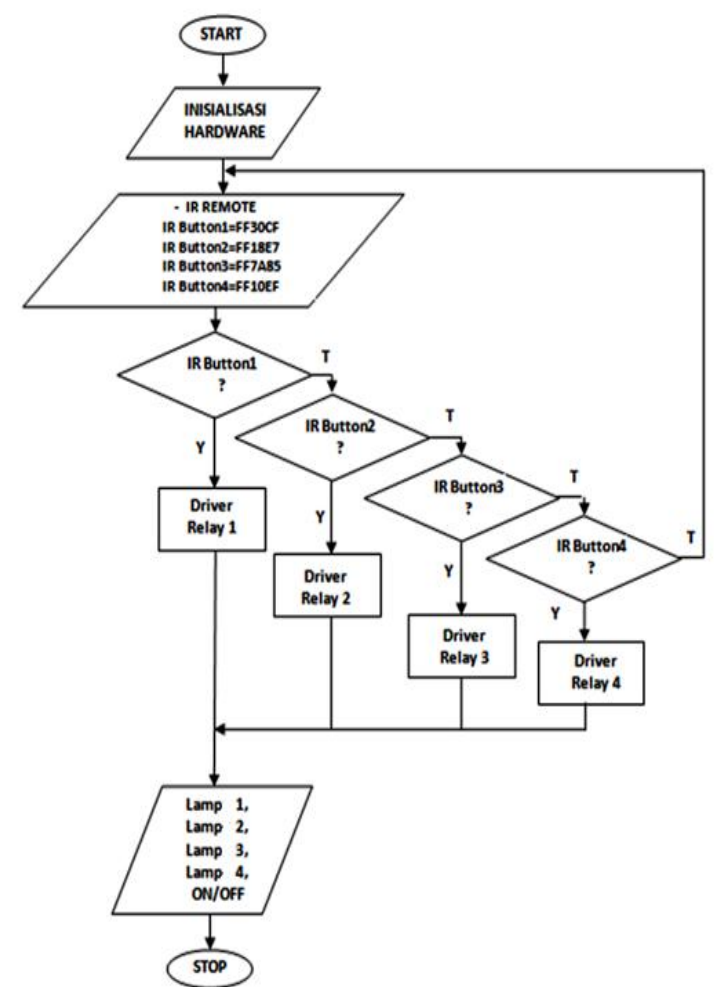

Figure 12. Emergency Light Control Flowchart

\section{TESTING SYSTEM}

\subsection{Emergency Light Control}

Testing is done to test the work of the remote control and the Arduino program in sending and receiving data. Testing is done to find out whether the data sent from the remote control has been successfully received and processed by Arduino. The test is carried out using a bread board (Figure 13) to place the emergency light control equipment after what is desired, then a control equipment panel is made (Figure 18).

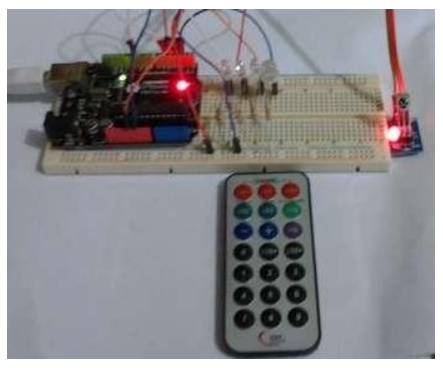

Figure 13. Testing Emergency Light Control with Bread Board

When the control system is activated and the remote button 1 is pressed, the microcontroller will process the data so that the Led1 indicator light will light up (figure 14). Likewise, for the indicator lights Led2, Led3 and Led4 (Figures: 15, 16 and 17).

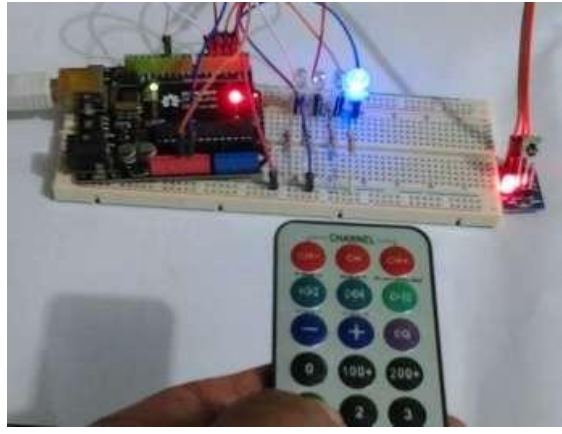

Figure 14. When Button 1 Remote Is Pressed

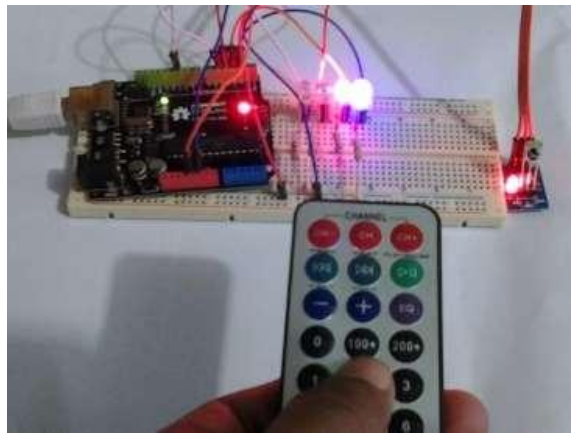

Figure 15. When Button 2 Remote Is Pressed

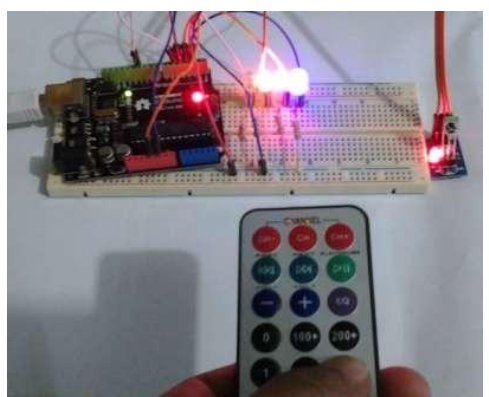

Figure 16. When Button 3 Remote Is Pressed

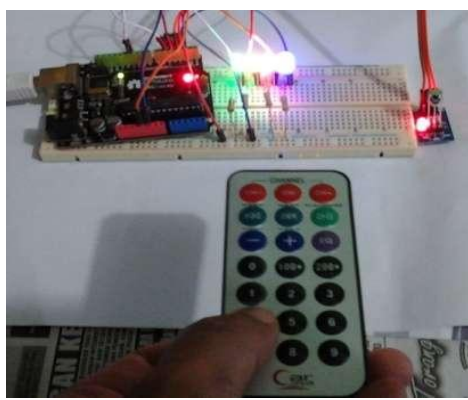

Figure 17. When Button 4 Remote Is Pressed

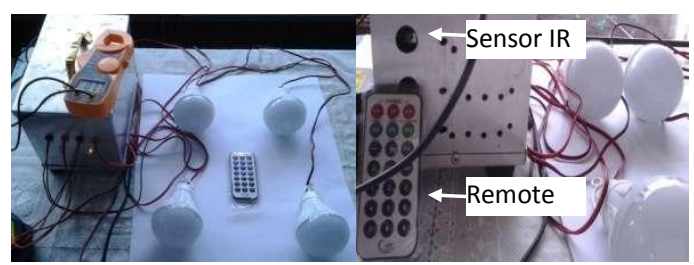

Figure 18. Emergency Light Control Equipment 


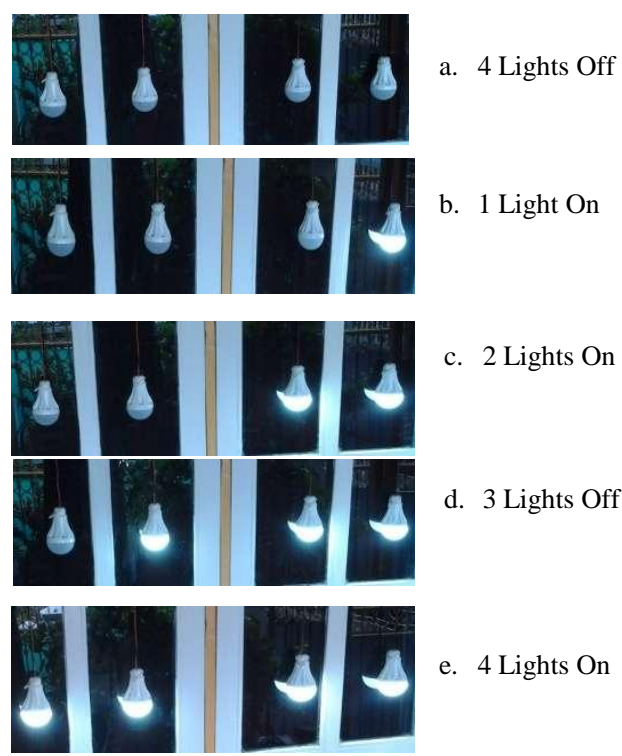

Figure 19. Control of 4 Emergency Lights

If the PLN goes out, the control circuit is supplied from the battery and the control circuit is ready to use with the LED indicator on.

When the button 1 on the remote is pressed, lamp1 will turn on, when button 1 is pressed again, lamp1 goes out. Likewise, for the buttons 2,3 and 4 on the remote when pressed.

When the PLN power source is on, the relay will work to stop the Emergency Light control and the battery will carry out the charging process.

\section{TESTING RESULTS}

\subsection{Test of Battery Capacity}

$\begin{array}{ll}\text { Voltage } & =12 \text { Volt } \\ 1 \text { Lamp 12 Vdc } & =7 \text { Watt } \\ \text { Lamp Current } & =7 / 12=0.583 \mathrm{~A}\end{array}$

Battery Capacity (Accu) $\quad=5 \mathrm{Ah}$

If the lamp is used $=1$

Total current $\quad=0.583 \times 1=0.583$ Ampere

Then the battery can last for:

$\begin{aligned} \text { Time } & =5 \mathrm{~A} / 0.583 \times 1 \text { hour } \\ & =8,576 \text { hours }\end{aligned}$

Lamps used $\quad=4$ pieces

Time $\quad=5 \mathrm{~A} / 2.332 \times 1$ hour

$=2.144$ hours

Table 1. Battery Capacity Time

\begin{tabular}{|l|c|c|c|}
\hline No. & $\begin{array}{c}\text { Lamp 7 } \\
\text { Watt }\end{array}$ & $\begin{array}{c}\text { Total Current } \\
\text { (Amp.) }\end{array}$ & $\begin{array}{c}\text { Time } \\
\text { (hours) }\end{array}$ \\
\hline 1 & 1 Pieces & 0.583 & \pm 8.5 hours \\
\hline 2 & 2 Pieces & 1.166 & \pm 4.3 hours \\
\hline 3 & 3 Pieces & 1.749 & \pm 2.8 hours \\
\hline 4 & 4 Pieces & 2.332 & \pm 2.1 hours \\
\hline
\end{tabular}

\subsection{Testing Distance between Transmitter (Remote Control) and Receiver (IR Sensor)}

This test aims to determine the ability of the Arduino Uno Microcontroller in processing incoming commands from the remote control with different control distances. So it takes several experiments to be able to see how far Arduino Uno is able to process the data sent by the remote control.

In this test, each lamp is tested according to a specified distance, namely at a distance of 1-7 meters by pressing 1-4 buttons on the remote control to turn the light on and off. When carrying out the test, the sensors by remote control are pointed without being obstructed by any objects. The ability of the IR (Infrared) sensor to detect signals from a remote distance of approximately 6 meters (Table 2 ).

Table 2. Distance Sensor IR Remote Signal Detecting Distance

\begin{tabular}{|c|l|l|l|l|}
\hline \multirow{2}{*}{$\begin{array}{c}\text { Distance } \\
\text { (meter) }\end{array}$} & \multicolumn{4}{|c|}{ Load Lamp } \\
\cline { 2 - 5 } & 1 & 2 & 3 & 4 \\
\hline 1 & On & On & On & On \\
\hline 2 & On & On & On & On \\
\hline 3 & On & On & On & On \\
\hline 4 & On & On & On & On \\
\hline 5 & On & On & On & On \\
\hline 6 & On & On & On & On \\
\hline 7 & Off & Off & Off & Off \\
\hline
\end{tabular}

\section{CONCLUSION}

From the results of the tests carried out, it can be concluded that the emergency lights with remote control using the Arduino Uno microcontroller can control emergency lights with a distance of up to 6 meters. The capacity of a battery with a capacity of $5 \mathrm{Ah}$ with a load of 4 lamps can last up to approximately 2 hours.

\section{THANK-YOU NOTE}

The authors would like to thank P3M Politeknik Negeri Manado and all those who can not be mentioned one by one so that this research can be done.

\section{REFERENCES}

[1] Abdul Kadir, A Practical Guide to Studying Microcontroller Applications and Its Programming Using Arduino, Andi Yogyakarta, 2013.

[2] Fina Supegina, Indra Septiadi, Design of Hospital Bluecode Emergency System Using Arduino Uno Microcontroller, Journal of Electrical Technology at Mercu Buana University ISSN: 2086-9479, Vol.6 No.2 May 2015.

[3] Heri Andrianto, Aan Darmawan, Arduino Fast Learning and Programming, Informatics Bandung, 2016.

[4] I Gede S. Widharma, Aan M. Narottama, Wayan Sudayana, Light Control Using AtMega 328 Microcontroller Based Remote, Department of Electrical Engineering, Bali State Polytechnic, JURNAL LOGIC Vol. 16. No.3 November 2016.

[5] Istiyanto Eko Jazi, Introduction to Electronics and Instrumentation Approach to the Arduino and Android Project, CV ANDI OFFSET, Yogyakarta, 2014. 
[6] Strong Indrartono, Teppei JL Tama, Achmad J. Mushtofa, STMIK Amikom Purwokerto, Wireless Emergency Button Based on Arduino Uno, Journal of TECHNO Vol.20, No.1, Hal. 17-22, P-ISSN: 1410-8607, E-ISSN: 2597-9096, April 2019.

[7] Sasongko, Bagus Hari, Microcontroller Programming in C. Yogyakarta Language: Andi, 2012.
[8] Sumardi, Microcontroller Learning AVR Starting From Zero. Yogyakarta: Graha Ilmu, 2013.

[9] Rizki Pratama Putra, Adimas Aglasia, Automatic Emergency Lamp, Faculty of Science, ComputerComputer Systems, Darmajaya Institute of Informatics and Business Bandar Lampung, ELECTRCIAN Journal of Electrical Engineering and Technology, Vol. 12. No.1, January 2018. 